\title{
DESIGN AND ANALYSIS OF DISPLACEMENT MODELS FOR MODULAR HORIZONTAL WIND TURBINE BLADE STRUCTURE
}

\author{
E. M. Etuk ${ }^{1, *}$, A. E. Ikpe ${ }^{2}$ and U. A. Adoh ${ }^{3}$ \\ 1, Dept of Production Engineering, University of Benin, P.M.B. 1154, Benin, Edo State, Nigeria \\ 2, DePt of MeChanical Engineering, University of Benin, P.M.B. 1154, Benin, Edo STATE, NIGERIA \\ 3,Technology Incubation Centre, Water Board Road, GRA, P.M.B 1107, Warri, Delta State, NIGERIA \\ E-mail addresses: 1 alwaysetuk@gmail.com, 2 aniekan.ikpe@eng.uniben.edu, \\ 3 adoh.azum@gmail.com
}

\begin{abstract}
This study examined the normal, radial, axial and tangential loading cycles undergone by wind turbine rotor blades and their effects on the displacement of the blade structure. The rotor blade was modelled using $Q$ Blade finite element sub module, which evaluated the loading cycles in terms of the forces induced on the blade at various frequencies through several complete revolution cycles ( $360^{\circ}$ each cycle). At frequencies of $5 \mathrm{~Hz}, 23 \mathrm{~Hz}, 60 \mathrm{~Hz}, 124 \mathrm{~Hz}$ and $200 \mathrm{~Hz}$, maximum strain deformation of 0.004, 0.04, 0.08, 0.14 and 0.24 were obtained, and geometry of the deformed blades were characterized by twisting and bending configuration. Maximum deflections from tangential loading increased from $-0.55-1.2 \mathrm{~mm},-0.39-1.6 \mathrm{~mm}$ from axial loading, $-0.28-1.8 \mathrm{~mm}$ from radial loading and $-0.01-2.3 \mathrm{~mm}$ from normal loading. From these deflection values, normal loading cycle would cause the highest level of structural damage on the rotor blade followed by radial, axial and tangential loading. Moreover, the strain deformations and deflections of the blade structure increased as the cycles of frequency increased.
\end{abstract}

Keywords: Loading cycle, Wind turbine, Rotor blade, Frequency, Strain deformations, Deflections.

\section{INTRODUCTION}

Energy plays a vital role in the growth and development of any nation. In other words, it is the backbone of industrial evolution in any economy. The energy generated from wind turbine is renewable and contributes to $20-40 \%$ of the overall energy usage in advanced countries. Wind turbine rotor blades during operation are exposed to high wind speeds and turbulent wind flow resulting from high pressure-high velocity wind speed that subjects them to vibrational frequencies at low and high amplitudes, thereby exposing the rotors to undesired loading cycles that may result in unforeseen catastrophes. This can cause failure of the rotor blade, if proper design consideration and routine maintenance are not put in place to avoid structural damages [1]. For example, blade material should have high stiffness value to be able to withstand bending loads and should also have high fatigue strength to be able to withstand other forms of loading cycles during operation $[2,3]$.

Despite the technological advancement in wind turbine rotor blade materials, failure which manifests in many forms is still a problem due to the various loading cycles during every revolution of the rotor blade. Manwell et al. [4] categorized wind turbine loads as steady load (static loads), cyclic load, stochastic load, transient and resonance-induced loads. Schubel and Crossley [5] carried out a detailed review on wind turbine blade design, and found from a basic load analysis that the turbine blade can be modelled as a simple beam with inbuilt support at the hub end.

The findings also revealed that a uniformly distributed load across the blade can be represented as aerodynamic lift during service operation of the wind turbine. To increase the structural integrity of wind turbine blade, Mouhsine et al. [6] developed

* Corresponding author, tel: +234 8025726325 
and analyzed a three dimensional horizontal-axis wind turbine blade using finite element method (FEM). The optimum blade geometry obtained showed significant deformation characterized by complex airfoil sections consisting of increasing width, thickness and twist angle towards the hub. Memon et al. [7] employed actuator surface hybrid model in the modelling route of a wind turbine of NREL phase VI to determine the effects of aerodynamic tangential forces in addition to normal forces on the wind turbine blade. The results revealed that normal forces are imposed as pressure discontinuity on the geometry which represent the turbine blades while tangential forces are imposed as source terms in the domain of the blades.

Dose et al. [8] investigated the effects of elastic blade deformations on the aerodynamics of large wind turbine rotors subjected to yawed inflow using Blade Element Momentum (BEM) theory and Computational Fluid Dynamics. It was observed that the impact resulting from structural deformations was more intense for tangential forces, leading to increase of about $5-10 \%$ deformation while the effect of structural deformations was more significant with increasing yaw angle. Harrison et al. [9] reported the loading results obtained from the analysis using BEM including airfoil rotation and BEM without the inclusion of airfoil rotation in order to determine airfoil rotation on load cycles. BEM with airfoil rotation indicated significant increase in the hub overturning moment compared to the simplified model. Increasing change was observed on the force components normal and parallel to the pitch axis which resulted in increasing blade deflection. Furthermore, the change in the distribution of forces along the blade led to changes in the blade bending moment.

In this study, a wind turbine rotor blade was modeled to examine the rate of strain deformations and deflections at various frequencies. Severity of different loading conditions on the blade models were also examined. This is meant to serve as a guideline for proper understanding of turbine blade failure modes and its effects, in order to mitigate against unforeseen failures in the design and operation phase of the rotor blades.

\section{DESIGN AND DEVELOPMENT OF THE ROTOR BLADE MODELS}

The wind load is a major factor in the wind turbine operation. It is the driving force that impacts motion on the rotor blade upon which other loading factors evolve. To understand the interplay between the rotor blade and the wind load in terms of deformations and deflections, wind field must be modelled to effectively represent the wind speed range in the domain intended for the rotor blade to perform as illustrated in Figure 1.

The horizontal wind turbine blade was modelled as a simple cantilever system (one end-fully constrained and the other end-unconstrained). The restrained end acts as the fulcrum of the blade, allowing rotation of the blade through angle of $360^{\circ} \mathrm{C}$ on each rotation cycle.

The modelling was done using $Q$ Blade Finite element sub module, which evaluates the forces in terms of loading cycles acting on the blade at various frequencies through each complete revolution. It also analyses the resultant effects on the rotor blade. It carries out a modal and deflection analysis on the blade model. Therefore, determines the optimum range of frequencies, which the blade can withstand due to forces from the wind and the stresses resulting thereof. Thus, guides the rotor blade against structural failure in service. Figure 2 shows typical results of analysis of the model.

Four (4) different categories of loading cycle were considered as the forces acting on the wind turbine blade during each complete revolution cycle, namely: normal loading due to vibration, axial loading due to wake loses, tangential loading or point load on certain sections of the blade due to wind direction, and radial loading due to cyclic motion of the blade within the domain of the wind field. The effects of the aforementioned loading cycles were investigated in terms of the blade deformation, which was taken as strain-elongation; and the blade deflection, as the deflection from the hub of the blade. The maximum deflection of the blade model under a point load was modelled using the equation of a point load on an elastic cantilever beam, as given in Equation (1):

$$
\delta_{\text {max }}=\frac{P L^{3}}{3 E I}
$$

where $\mathrm{E}$ is Young's modulus of the blade material, $\mathrm{P}$ is the tangential load, $I$ is the second moment of area, and $L$ is the blade length.

For normal uniformly distributed wind loading on the blade, the maximum deflection was modelled using Equation (2). The equation is a typical deflection equation of an elastic cantilever system under uniformly distributed loads [10].

$$
\delta_{\max }=\frac{w L^{4}}{8 E I}
$$


Or

$$
\delta_{\max }=\frac{P L^{3}}{8 E I}
$$

Where $\mathrm{P}=w L, \mathrm{w}$ is uniformly distributed load along the blade cross section.

In this case, the second moment of area $I$ of the rotor blade as indicated Equation (1-3) is given by Equation (4) $[11]$.

$$
I=\frac{b h^{3}}{12}
$$

where $b$ and $h$ are the breath and height of the turbine blade.

The natural frequency factor for a cantilever system under point load is given by Equation (5):

$$
\omega_{n}=\sqrt{\frac{3 E I}{m L^{3}}}
$$

where $m$ is the mass of the rotor blade.

Substituting the expression of the second moment of area, I in Equation (4) into Equation (5), gives:

$$
\omega_{n}=\frac{(\beta R)_{i}^{2}}{R^{2}} \sqrt{\frac{E I}{\widetilde{\rho}}}
$$

Where $I$ is the area moment of inertia, $E$ is the modulus of elasticity, $\tilde{\rho}$ is the mass per unit length of the rotor blade, $\mathrm{R}$ is constant, $(\beta R)_{i}^{2}$ is the series constant. Equation (7) can also be expressed as;

$$
\omega_{n}=\frac{(\beta R)_{i}^{2}}{R^{2}} \sqrt{\frac{E c t^{3}}{12 \rho_{b} c t}}=\frac{(\beta R)_{i}^{2}}{R^{2}} t \sqrt{\frac{E}{12 \rho_{b}}}
$$

where $\mathrm{c}$ and $\mathrm{t}$ represents the chord length (breadth, b) and thickness, $t$ of the rotor blade respectively. $\tilde{\rho}=\rho_{\mathrm{b}} \times \mathrm{c} \times \mathrm{t}$ (mass density of the rotor blade).

For operating frequencies conditions between $30 \%$ and $140 \%$ of the tower natural frequency, a dynamic magnification factor, $D$ given in Equation (8) is multiplied by the design loads for accuracy $[12,13]$.

$$
D=\frac{1}{\sqrt{\left[1-\left(f_{e} / f_{n}\right)^{2}\right]^{2}+\left[2 \xi\left(f_{e} / f_{n}\right)^{2}\right]}}
$$

where $f_{e}$ is the excitation frequency, $f_{n}$ is the natural frequency, $\xi$ is the damping ratio obtained from the logarithmic damping decrement given by Equation (9);

$$
\xi=\frac{\delta}{2 \pi}
$$

In conditions where the frequency of the excitation reduces significantly during operation, this can be expressed by the relation in Equation (10);

$$
k=\frac{\omega c}{2 U_{\text {rel }}}
$$

where $\omega$ designates circular frequency of the excitation, $c$ is the local blade chord length and $U_{\text {rel }}$ is the local flow velocity relative to the blade section.

Considering the time between amplitudes, the undamped $\left(\omega_{n r}\right)$ and damped $\left(\omega_{d r}\right)$ periods of vibration is given by Equations (11) and (12) respectively [14].

$$
\begin{aligned}
& \omega_{n r}=\frac{2 \pi}{\tau_{d} \sqrt{1-\xi_{b z}^{2}}} \\
& \omega_{d r}=\frac{2 \pi}{\tau_{d}}
\end{aligned}
$$

where, $\tau \mathrm{d}$ is the damped period of vibration.

The average linear strain, $e$ is the ratio of the change in length, $\Delta \mathrm{L}$ to the original length $L_{o}[15]$. For the rotor blade material, the average strain which is a function of the rotor blade deformation on loading cycles can be expressed in the following relation;

$$
e=\frac{\delta}{L_{o}}=\frac{\Delta L}{L_{o}}=\frac{L-L_{a}}{L_{o}}
$$
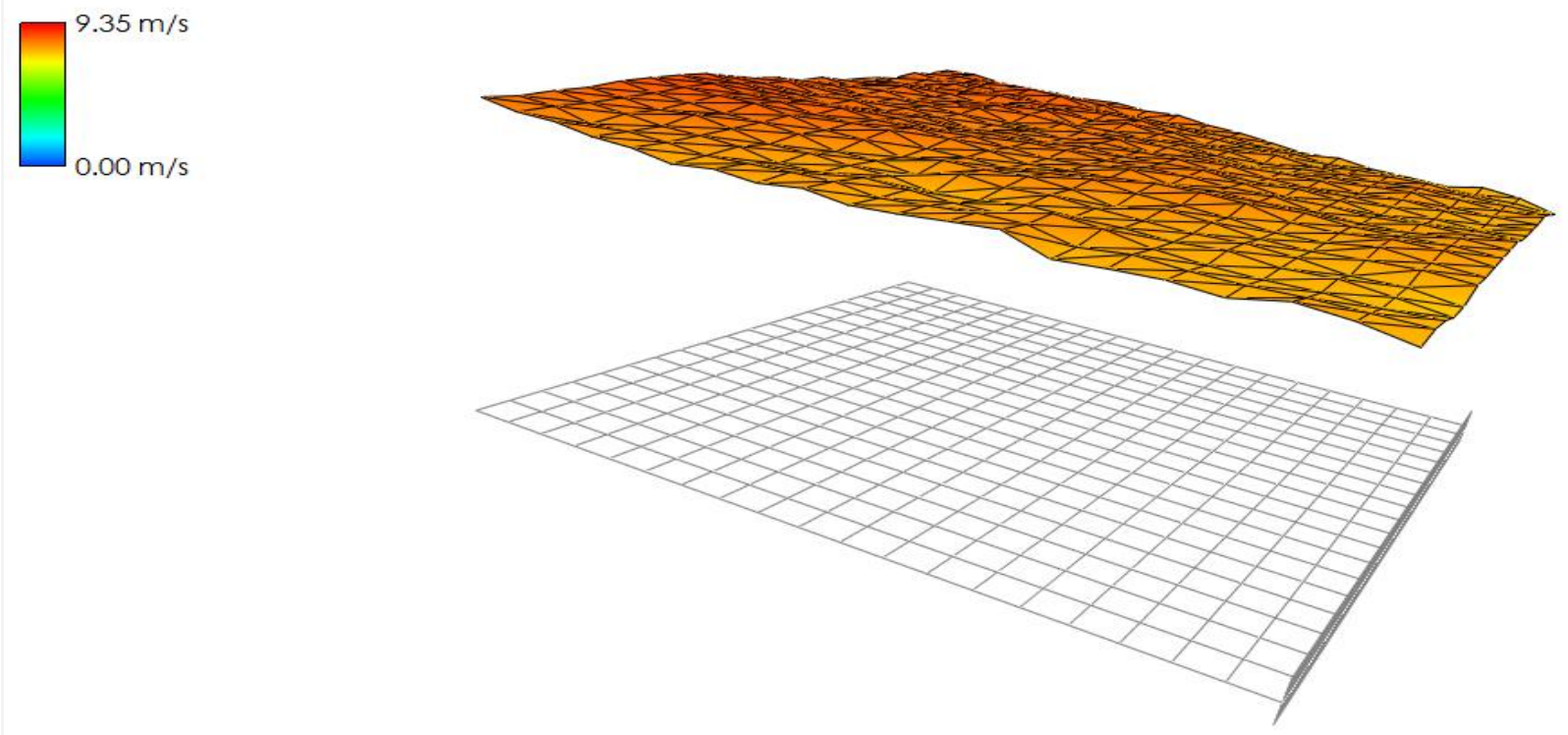

Fig. 1: Wind field model at windspeed ranging from $0-9.35 \mathrm{~m} / \mathrm{s}$ 


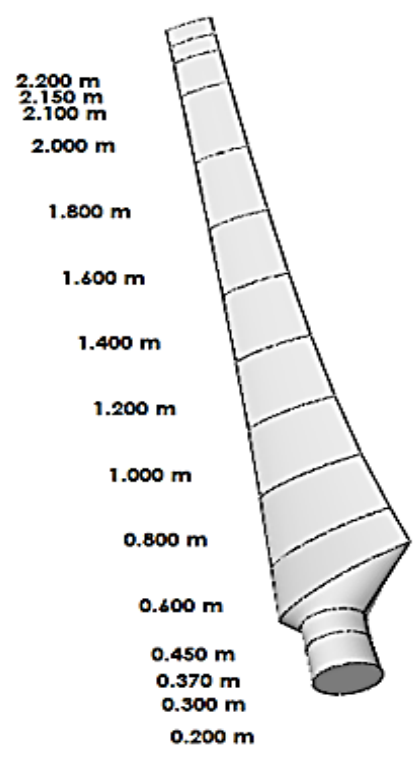

\begin{tabular}{|c|c|c|c|}
\hline \multicolumn{4}{|c|}{ Blade Geometrv/Root Coordinates } \\
\hline & Pos (m) & Chord (m) & Twist \\
\hline $\mathbf{1}$ & $\mathbf{0}$ & 0.18 & $\mathbf{0}$ \\
\hline 2 & 0.1 & 0.15 & $\mathbf{0}$ \\
\hline 3 & 0.17 & 0.15 & $\mathbf{0}$ \\
\hline 4 & 0.25 & 0.445329 & 22.0984 \\
\hline 5 & 0.4 & 0.358177 & 15.0535 \\
\hline 6 & 0.8 & 0.280741 & 9.1363 \\
\hline 7 & 0.8 & 0.229543 & 5.34817 \\
\hline $\mathbf{8}$ & $\mathbf{7}$ & 0.193644 & 2.73627 \\
\hline 9 & 1.2 & 0.187236 & 0.833645 \\
\hline 10 & 1.4 & 0.147058 & -0.611142 \\
\hline 1 1 & 1.8 & 0.131167 & -1.74427 \\
\hline 12 & 1.8 & 0.118341 & -2.65811 \\
\hline 13 & 1.8 & 0.112814 & -3.04823 \\
\hline 14 & 1.95 & 0.110241 & -3.23097 \\
\hline 15 & 2 & $0.10>78$ & -3.40536 \\
\hline \multicolumn{3}{|c|}{ New } & Edit \\
\hline
\end{tabular}

Fig. 2: Blade Geometry/Root Coordinates

If the strain is too small, it can be referred to as infinitesimal normal strain, which is the infinitesimal change in length, $d L$, of a line given by Equation (14); $d \varepsilon=\frac{d L}{L}$

Integrating from the original length, $L_{o}$ to the final length, $L$, the true strain is obtained as;

$\varepsilon=\int \frac{d L}{L}=1 n\left(\frac{L}{L_{o}}\right)$

The relationship between true strain and conventional linear strain on the material is given by;

$\left|\begin{array}{c}e=\frac{\Delta L}{L_{o}}=\frac{L-L_{o}}{L_{o}}=\frac{L}{L_{o}}-1 \\ e+1=\frac{L}{L_{o}} \\ \varepsilon=1 n \frac{L}{L_{o}}=1 n(e+1)\end{array}\right|$

\section{RESULTS AND DISCUSSION}

Figures 3-7 illustrate deformations on the blade geometry and the 3-dimensional plot of the deformed blade shape at different Frequencies of $5 \mathrm{~Hz}, 23 \mathrm{~Hz}$, $60 \mathrm{~Hz}, 124 \mathrm{~Hz}$ and $200 \mathrm{~Hz}$. The deformation in this case is as a result of strain effect, as the blade material undergoes many frequency cycles due to vibrational effect (which can also cause bending of the rotor blade) in one complete revolution of $360^{\circ}$.

In similar studies carried out by Kallesoe and Hansen [16], it was revealed that the first edgewise bending mode becomes negatively damped due to the coupling with blade torsion, which results in a change of the effective direction of the blade vibration. In this case, deformation rate in the blade material, which is a function of strain may increase in response to increasing load cycles and vibration frequencies. This causes an increase in strain along the bonded area within the atoms in the lattice of the blade material; thereby, twisting the blade and altering its geometry from the original shape. This is obsevered in Figures $3-7$, which clearly indicate that increasing the rotor blade frequencies resulted in increase in loading cycles which in turn causes increase in the rate of deformations. Maximum strain deformation as depicted in the 3D plot of Figure $3 b$ is 0.004 at frequency of $5 \mathrm{~Hz}$. This does not show significant deformation on the blade geometry as shown in Figure 3a. The direction lebeled " $L(\mathrm{~mm})^{\prime \prime}$ on the 3D plot represents the length of the rotor blade. At frequency of $23 \mathrm{~Hz}$, the maximum strain deformation as depicted in the 3D plot of Figure $4 \mathrm{~b}$ is 0.04 .

There is also no significant deformation in the blade geometry as shown in Figure 4a. However, at frequency of $60 \mathrm{~Hz}$, maximum strain deformation as depicted in the 3D plot of Figure $5 \mathrm{~b}$ rose to 0.08 . The blade geometry begins to deform noticeably as shown in Figure 5a. Then, at frequency of $124 \mathrm{~Hz}$ and 200 $\mathrm{Hz}$, the maximum strain deformations as depicted in Figure $6 \mathrm{~b}$ and Figure $7 \mathrm{~b}$ increased significantly up to 0.14 and 0.24 respectively. The significant deformations are also observed in Figure $6 a$ and Figure 7a respectively. Sompong and Prombut [17] referred to the blade deformation as blade twist. This they said would have significant effect on the power output of the blade.

In the design of a Wind turbine system, a cut-in wind speed, rated wind speed as well as a cut-out wind speed is incorporated for effective performance. In 
conditions where the wind turbine operates under the influence of cut-in speed, the rotor blades begin to gain turning momentum and starts producing trickle of electricity. During the cut-in speed period which typically falls in the range of 3 and $4 \mathrm{~m} / \mathrm{s}$ the generator can serve as a motor to enable the wind overcome inertia for the blades to start rotating. When the wind turbine operates at a rated wind speed which is about $11-15 \mathrm{~m} / \mathrm{s}$, it is able to generate power output in terms of electricity at maximum or rated capacity. However, at the cut-out wind speed which is about $20-24 \mathrm{~m} / \mathrm{s}$, the wind turbine system shuts down by itself in order to avoid damages to its operating components [18]. During this period, the rotor blades are shielded by the pitch controllers to allow the wind flow past them, while the brake in the rotor hub is triggered [19]. Figures 8-12 show the structural analysis of the wind turbine blade carried out under different forms of loading: normal, axial, radial and tangential loading. The analysis considered the cut in speed as the idle mode, while the rated speed was taken as the active mode.

As shown in Figure 8, at a frequency of $5 \mathrm{~Hz}$, the maximum deflection of $-0.01 \mathrm{~mm}$ is induced on the rotor blade at normal loading cycle of $2.1 \mathrm{~N}$ in the active mode. Deflection values obtained for the rotor blade in idle mode also indicate negative sign. This implies that in scenarios where the rotor blade is subjected to a frequency of $5 \mathrm{~Hz}$ for both idle mode and active mode, no significant deflection may be observed. It should be noted that the said deflection occurs during rotation as a result of the rotor blade displacement from its root (turbine shaft) enclosed by the hub.

For radial loading, axial and tangential loading circles; the maximum deflections are of $-0.28 \mathrm{~mm}, 0.39 \mathrm{~mm}$ and $-0.55 \mathrm{~mm}$ respectively at a loading cycles of 2.1 $\mathrm{N}, 2.2 \mathrm{~N}$ and $2.1 \mathrm{~N}$ respectively. The tangential loading cycle had the least value, while that of normal loading cycle had the highest value. This is because, tangential loading, which acts on a point/section of the blade occurs rarely; as the blade is most of the times in cyclic motion. The cyclic motion does not give room for point contact between the wind direction and the blade; rather, the wind flows following the streamline pattern of air foil trajectory within the wind field.

From Figure 9, at a frequency of $23 \mathrm{~Hz}$, the maximum deflection of $0.66 \mathrm{~mm}$ is induced on the rotor blade at normal loading cycle of $2.1 \mathrm{~N}$ in the active mode. For other loading conditions: radial, axial and tangential loading, the maximum deflections gave $0.5 \mathrm{~mm}, 0.28$ $\mathrm{mm}$ and $0.15 \mathrm{~mm}$ at a loading cycles of $2.1 \mathrm{~N}, 2.2 \mathrm{~N}$ and $2.1 \mathrm{~N}$ respectively.

Deflection values obtained for the rotor blade in idle mode also indicate negative sign as in the case of $5 \mathrm{~Hz}$ frequency. This is because at idle mode, the wind speed struggles to impact turning momentum on the rotor blade, as such, no damage occurs in terms of the blade deflection during such condition. Though, deflections do occur in the active mode depending on the frequency as observed in this case.

Figure 10 showed that at a frequency of $60 \mathrm{~Hz}$, maximum deflection of $1.6 \mathrm{~mm}$ is induced on the rotor blade at normal loading cycle of $2.1 \mathrm{~N}$ in the active mode. For other loading conditions: radial, axial and tangential loading, the maximum deflections gave 1.3 $\mathrm{mm}, 0.9 \mathrm{~mm}$ and $0.84 \mathrm{~mm}$ at a loading cycles of 2.0 $\mathrm{N}, 2.1 \mathrm{~N}$ and $2.2 \mathrm{~N}$ respectively.

Maximum deflection value obtained from the blade at a frequency of $60 \mathrm{~Hz}$ is comparably higher than those from frequencies of $23 \mathrm{~Hz}$ and $5 \mathrm{~Hz}$.

At a frequency of $124 \mathrm{~Hz}$, maximum deflection of 2.3 $\mathrm{mm}$ is induced on the rotor blade at normal loading cycle of $2.1 \mathrm{~N}$ in the active mode as shown in Figure 11. For other loading conditions: radial, axial and tangential loading, the maximum deflections gave 1.8 $\mathrm{mm}, 1.6 \mathrm{~mm}$ and $1.2 \mathrm{~mm}$ at a loading cycles of $2.0 \mathrm{~N}$, $2.2 \mathrm{~N}$ and $2.1 \mathrm{~N}$ respectively.

These deflection-loading cycles relationships at the various frequencies showed gradual increase in deflection values obtained from the rotor blade, as the frequency increases. That is, deflections at $124 \mathrm{~Hz}$ frequency is comparably higher than deflections from other lower frequencies: $5 \mathrm{~Hz}, 23 \mathrm{~Hz}$ and $60 \mathrm{~Hz}$. This trend relates to previous studies by Kallesoe and Hansen [16], where slight decrease was observed in flutter limit of the rotor speed as a result of the blade deflection.

As shown in Figure 12, the maximum deflection of 3.2 $\mathrm{mm}$ at a frequency of $200 \mathrm{~Hz}$ is induced on the rotor blade at normal loading cycle of $2.1 \mathrm{~N}$ in the active mode. For other loading conditions: radial, axial and tangential loading, the maximum deflections gave 2.7 $\mathrm{mm}, 2.2 \mathrm{~mm}$ and $1.6 \mathrm{~mm}$ at a loading cycles of $2.0 \mathrm{~N}$, $2.2 \mathrm{~N}$ and $2.1 \mathrm{~N}$ respectively.

Deflection obtained at a frequency of $200 \mathrm{~Hz}$ was observed to be again higher than that of $124 \mathrm{~Hz}$; and other lower frequencies. Thus, just as in Sompong [17], rotor blade deflection has little effect on the wind turbine power coefficient, whereas, Pechlivanoglou et al. [20] observed in their findings that positive flap deflections can significantly increase lift with 
considerable drag penalties which decrease the liftdrag ratio. In addition, negative flap deflection causes large reduction in lift and could be very instrumental to wind turbine rotor deceleration.

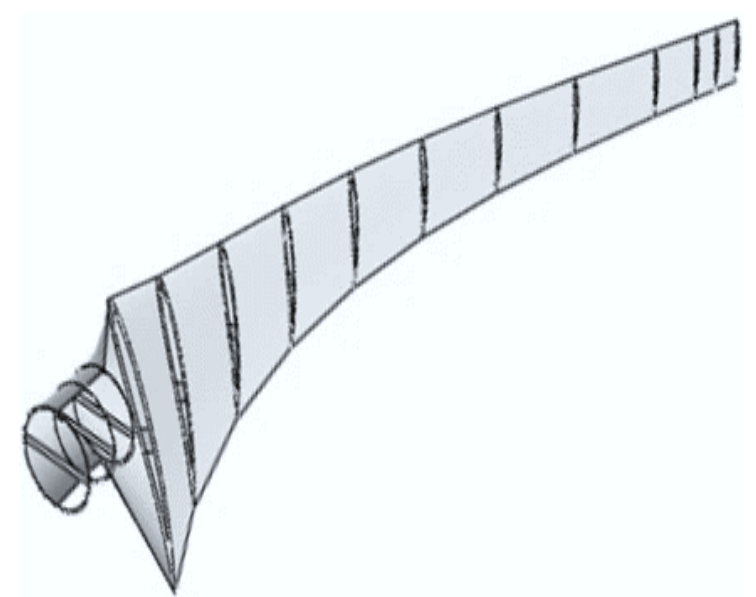

Fig. 3a: Blade deformation at frequency of $5 \mathrm{~Hz}$

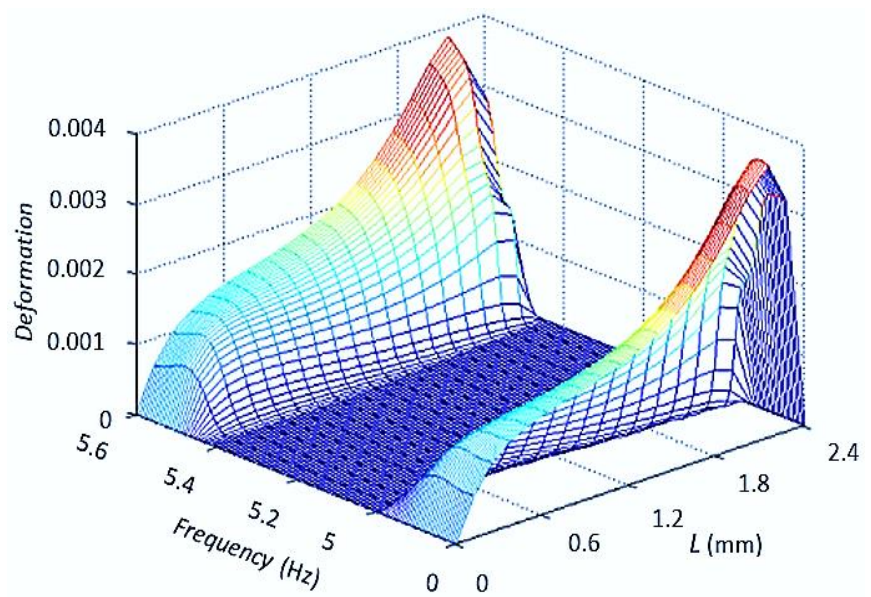

Fig. 3b: 3D plot of Blade deformation at frequency of $5 \mathrm{~Hz}$

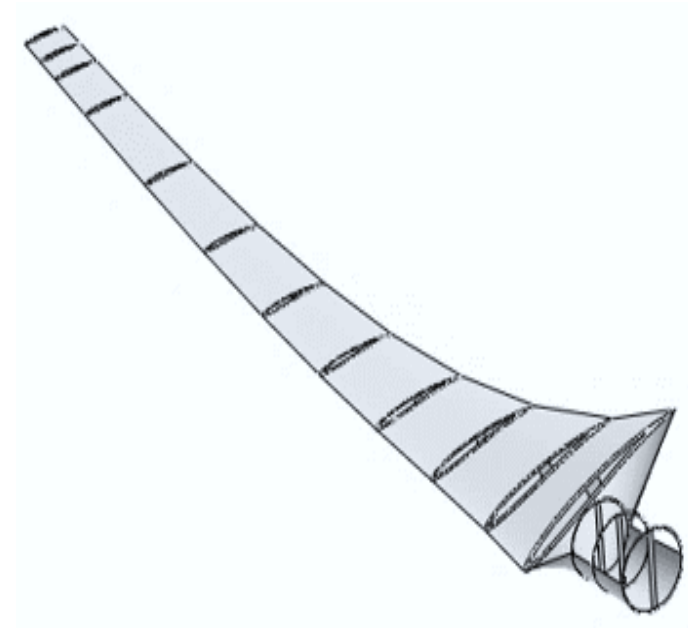

Fig. 4a: Blade deformation at frequency of $23 \mathrm{~Hz}$

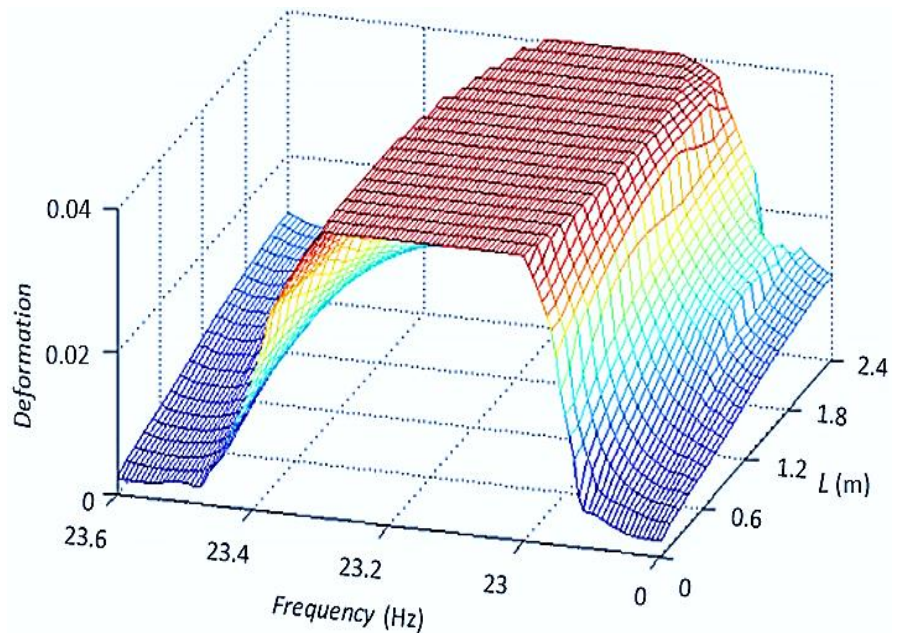

Fig. 4b: 3D plot of Blade deformation at frequency of $23 \mathrm{~Hz}$

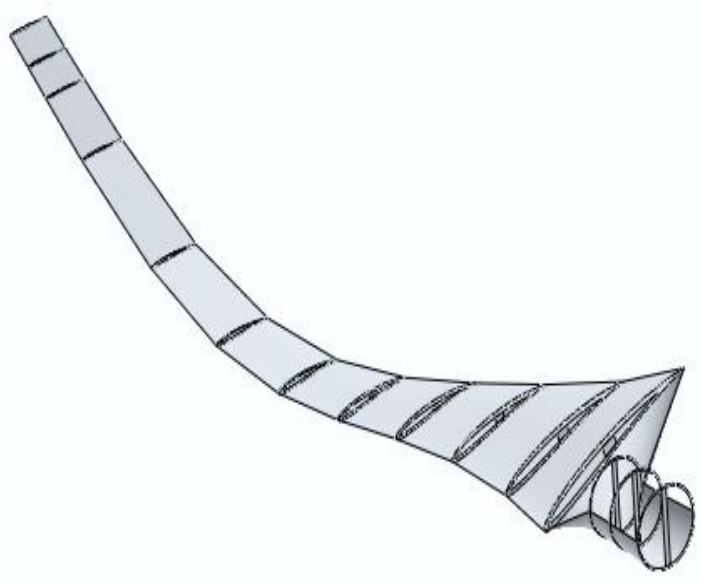

Fig. 5a: Blade deformation at frequency of $60 \mathrm{~Hz}$

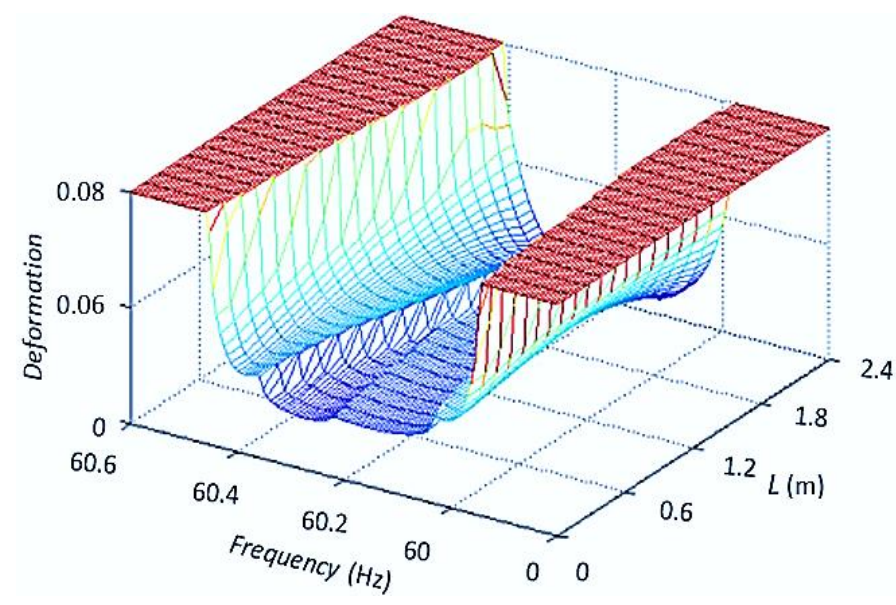

Fig. 5b: 3D plot of Blade deformation at frequency of $60 \mathrm{~Hz}$ 


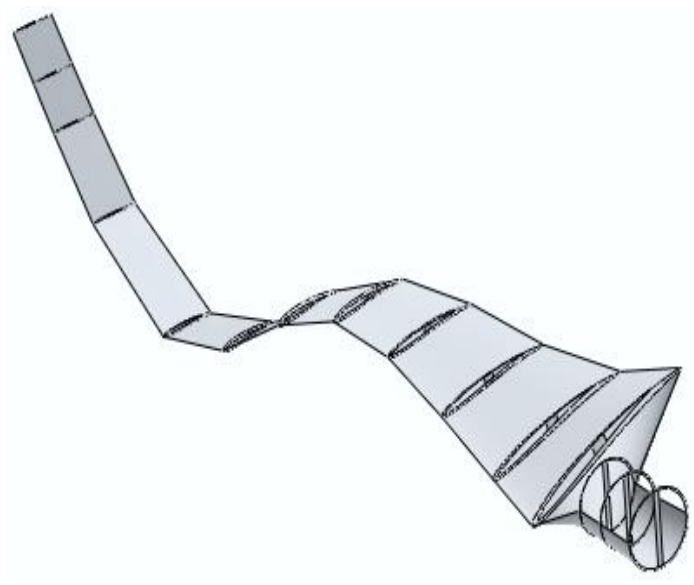

Fig. 6a: Blade deformation at frequency of $124 \mathrm{~Hz}$

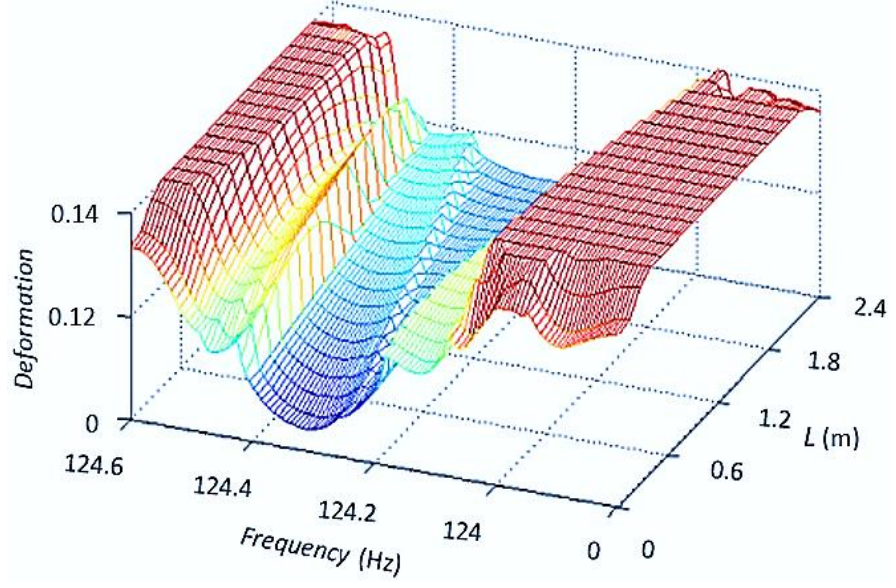

Fig. 5: 3D plot of Blade deformation at frequency of $124 \mathrm{~Hz}$

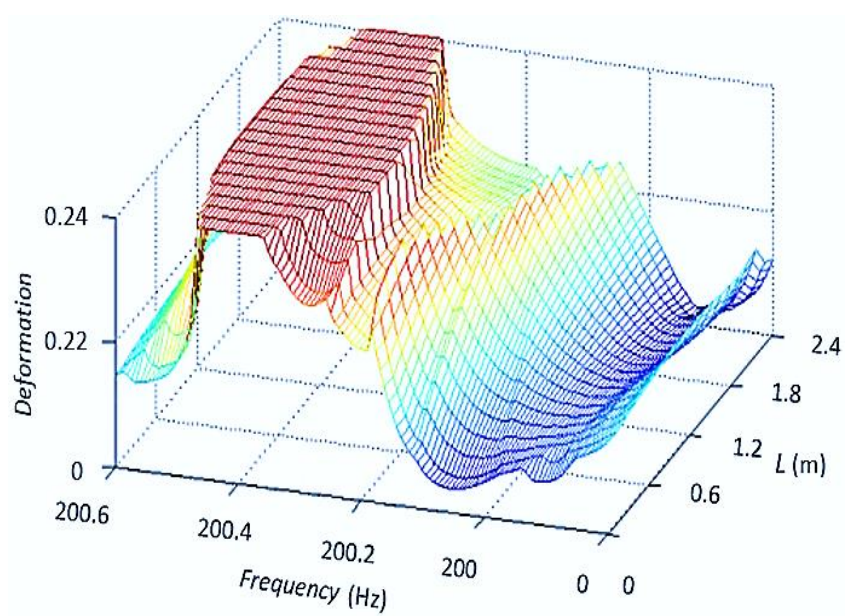

Fig. 7b: 3D plot of Blade deformation at frequency of 200 $\mathrm{Hz}$
Fig. 7a: Blade deformation at frequency of $200 \mathrm{~Hz}$

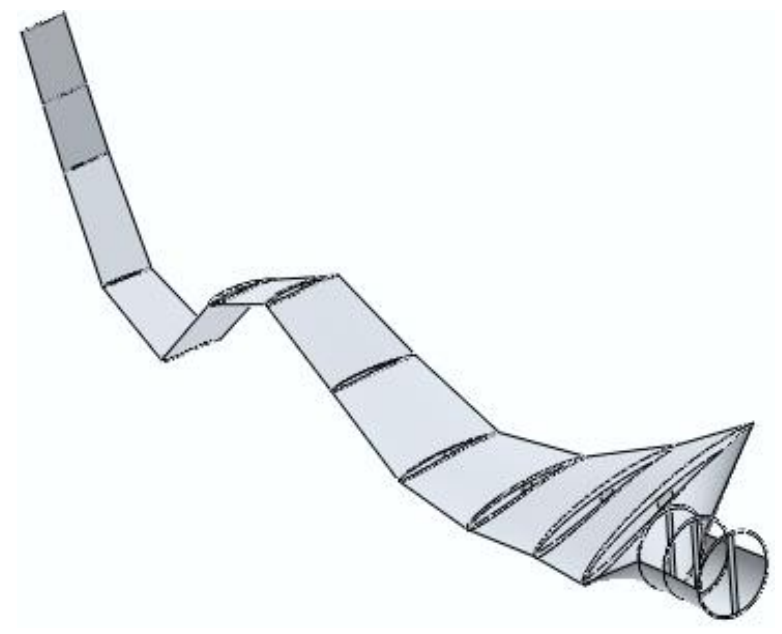

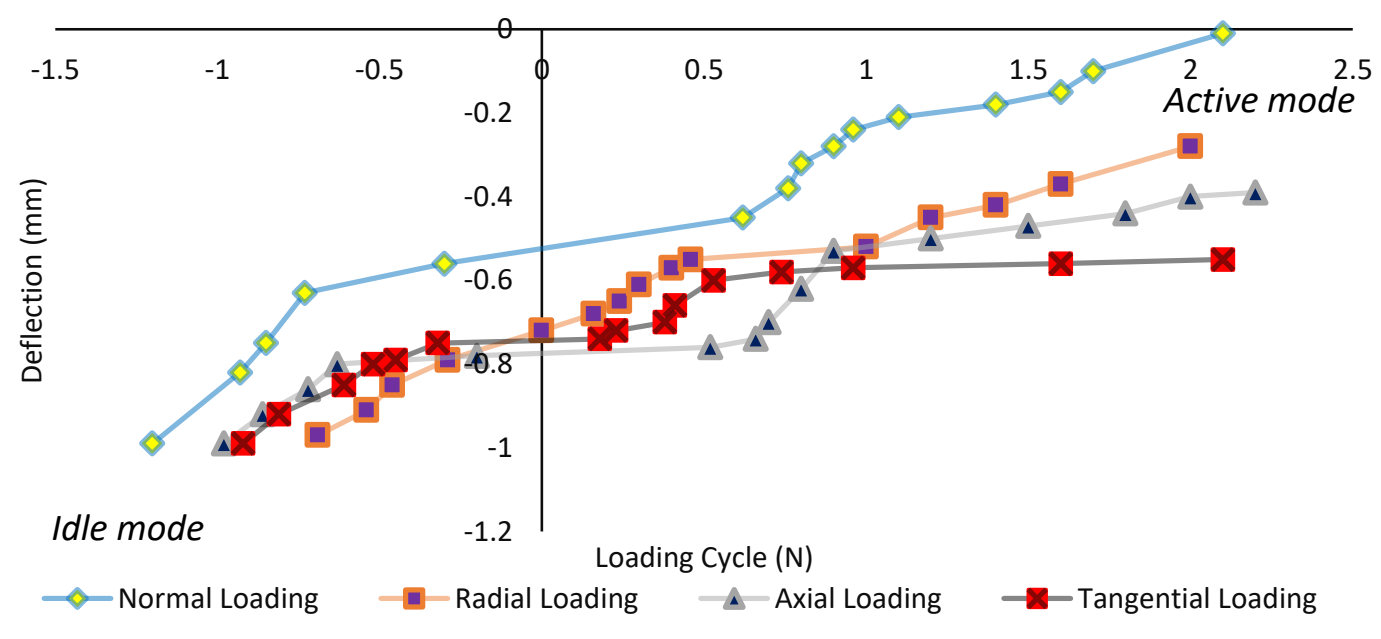

Fig. 8: Blade deflection resulting from loading cycle at a frequency of $5 \mathrm{~Hz}$ 


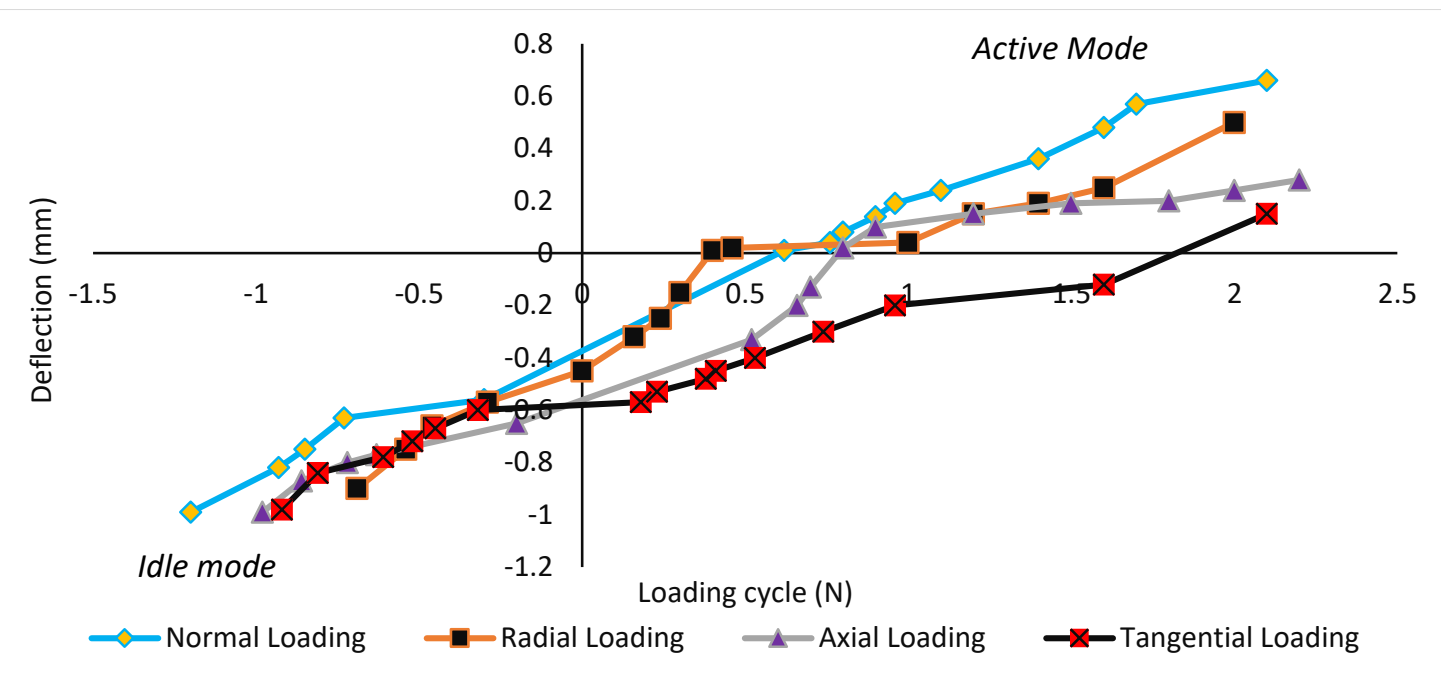

Fig. 9: Blade deflection resulting from loading cycle at a frequency of $23 \mathrm{~Hz}$

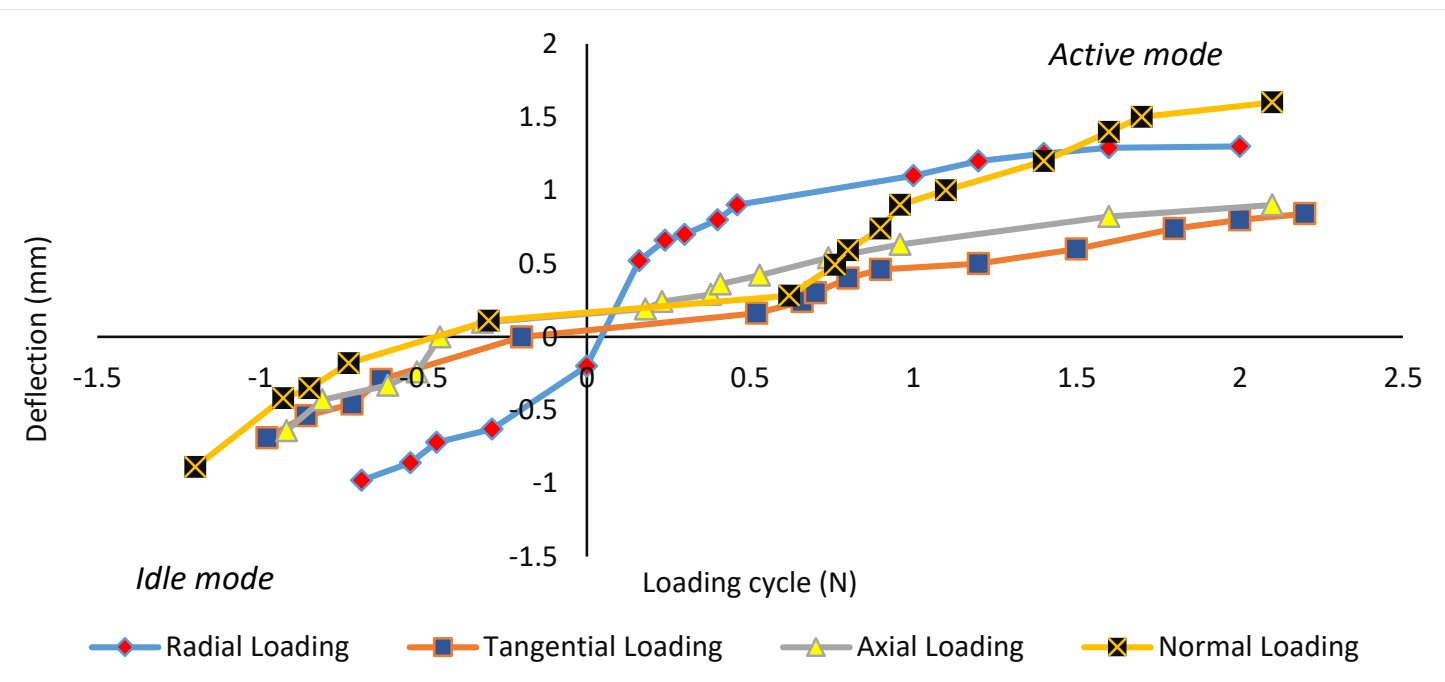

Fig. 10: Blade deflection resulting from loading cycle at a frequency of $60 \mathrm{~Hz}$

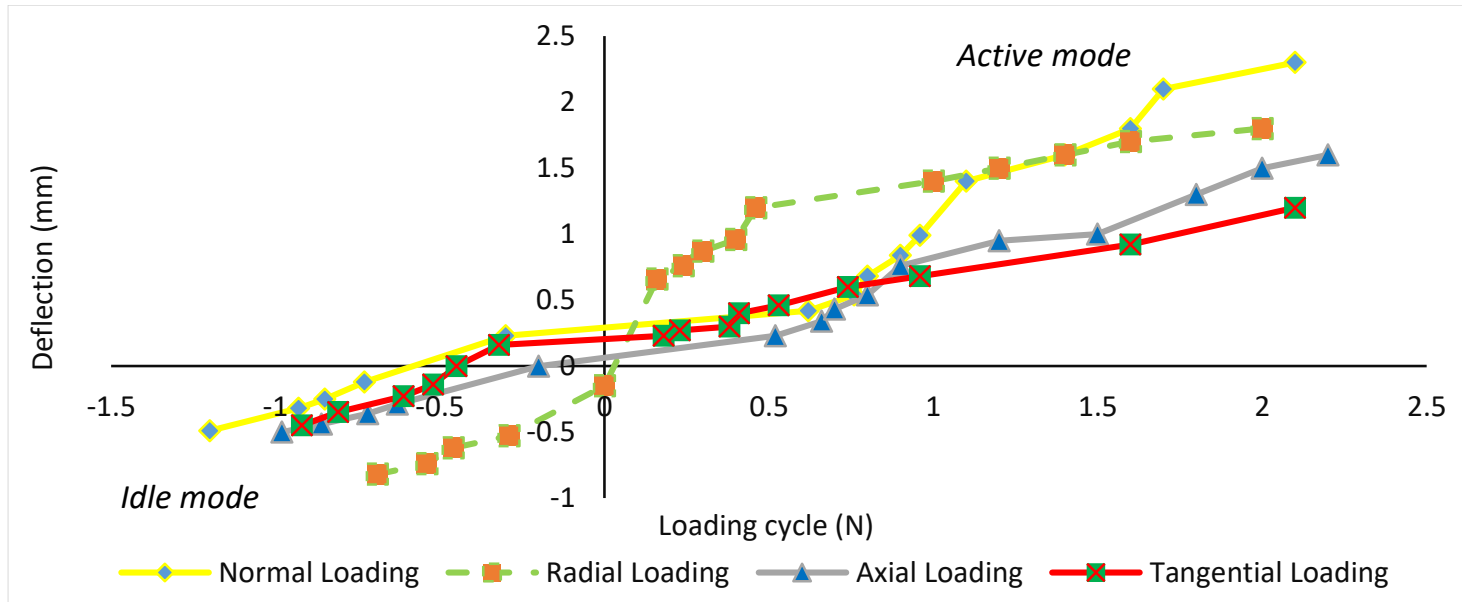

Fig. 11: Blade deflection resulting from loading cycle at a frequency of $124 \mathrm{~Hz}$ 


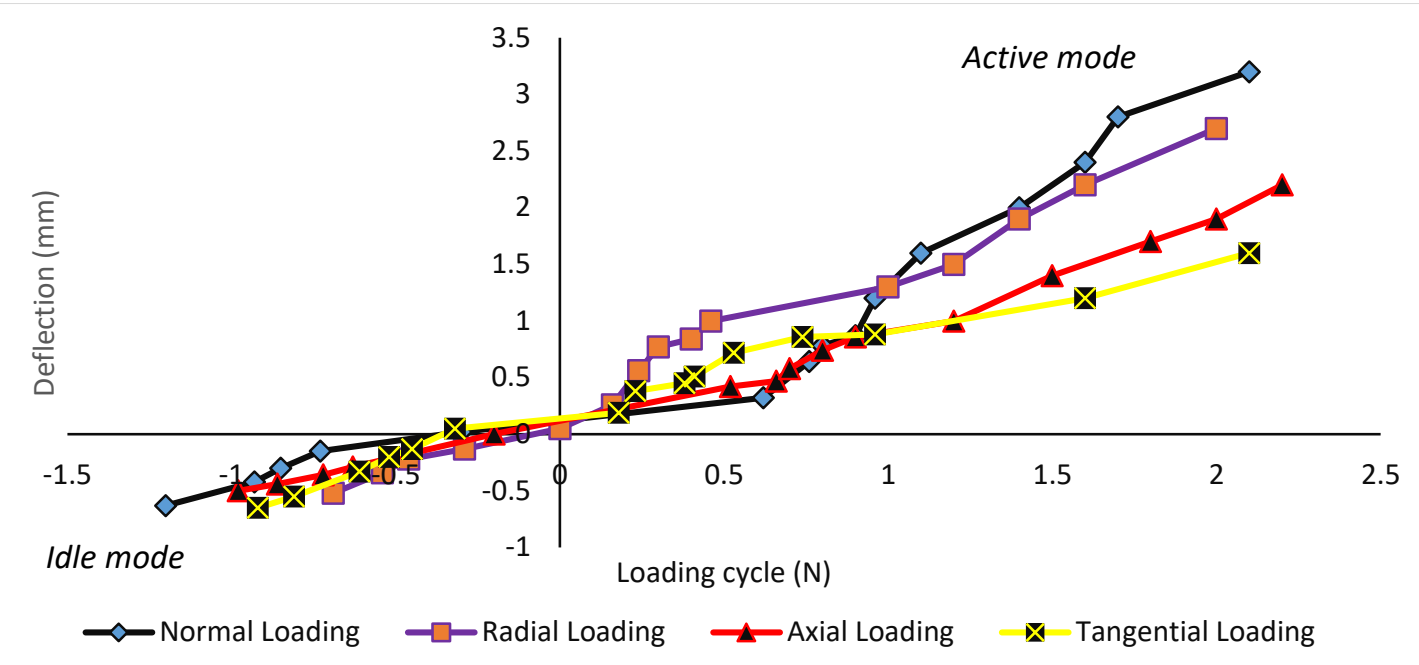

Fig. 12: Blade deflection resulting from loading cycle at a frequency of $200 \mathrm{~Hz}$

\section{CONCLUSION}

In this study, Q Blade finite element sub module has been successfully employed in the investigation of strain deformations and deflections of a wind turbine rotor blade due to in-service loading cycles at various frequencies. The following conclusions are therefore adduced:

a. strain-deformation and deflection failure mode of rotor turbine in normal, radial, axial and tangential loading conditions becomes significant with rotor turbine frequencies of $60 \mathrm{~Hz}$ and above.

b. blade deformations and deflections at frequencies of $60 \mathrm{~Hz}$ and above could significantly affect the blade efficiency, structural integrity of the wind turbine components, as well as the overall performance of the wind turbine system.

c. improper streamlined blade geometries could undergo rapid twisting and bending due to wake effects which translates into turbulent flow. This prevents the turbine blade from rotating with ease, thereby, causing reduction in the amount of energy yield.

d. wind turbine blade operating above wind speed capacity of $20 \mathrm{~m} / \mathrm{s}$ (cut-out speed) becomes detrimental to the structural integrity of the blade and performance of rotating members (such as gears, bearings etc.) in the system.

Based on the strain deformations and deflections clearly presented in this study, the following recommendations are made: a. routine checks and maintenance is recommended on wind turbine rotor blades for effective performance and longevity.

b. horizontal wind turbine blades must be designed to allow yaw inflow, so as to orient themselves in line with wind direction. In this case, a mechanism should be incorporated to enable the yawing motion take place, but at a slow rate to minimize large gyroscopic forces.

c. more suitable wind turbine blade designs should be investigated for improved geometric features against its in-service loading conditions, taking cognizance of the blade materials.

\section{REFERENCES}

[1]. Ismaiel, A. and Yoshida, S. (2019) Aeroelastic analysis of a coplar twin-rotor wind turbine. Energies, 12(1881), 1-21.

[2]. Ikpe, A. E., Owunna, I., Ebunilo, P. O. and Ikpe E. (2016a) Material selection for high pressure (HP) compressor blade of an aircraft engine. International Journal of Advanced Materials Research, 2(4), 59-65.

[3]. Ikpe, A. E., Owunna, I., Ebunilo, P. O. and Ikpe E. (2016b) Material selection for high pressure (HP) turbine blade of conventional turbojet engines. American Journal of Mechanical and Industrial Engineering, 1(1), 1-9.

[4]. Manwell, J. F., McGowan, J. G. and Rogers, A. L. (2002) Wind energy explained-theory, design and application. John Wiley \& Sons Ltd, ISBNs: 0-471-49972-2. 
[5]. Schubel, P. J. and Crossley, R. J. (2012) Review: Wind turbine blade design. Energies, 5, 3425-3449.

[6]. Mouhsine, S., Oukassou, K., Ichenial, M. M., Kharbouch, B. and Hajraoui, A. (2018) Aerodynamics and structural analysis of wind turbine blade. Procedia Manufacturing, 22, 747-756. $11^{\text {th }}$ International Conference on Interdisciplinarity in Engineering, 5-6 October 2017, Tirgu-Mures, Romania.

[7]. Memon, A., Samo, S. R., Asad, M. and Mangi, F. H. (2015) Modelling of aerodynamic forces on the wind turbine blades. Journal of Clean Energy Technologies, 3(6), 406-410.

[8]. Dose, B., Rahimi, H., Stoevesandt, B., Peinke, J. and Schepers, J. G. (2018) On the effect of blade deformations on the aerodynamic performance of wind turbine rotors subjected to yawed inflow. IOP Conference Series, Journal of Physics: Conference Series, 1037 (2018), 022030.

[9]. Harrison, M., Kloosterman, M. and Urbano, R. B. (2018) Aerodynamic modelling of wind turbine blade loads during extreme deflection events. IOP Conference Series, Journal of Physics: Conference Series, 1037 (2018), 062022.

[10]. Ikpe, A. E., Owunna, I. B. and Satope, P. (2017) Design optimization of a B-pillar for crashworthiness of vehicle side impact. Journal of Mechanical Engineering and Sciences, 11(2), 2693-2710.

[11]. Owunna, I., Ikpe, A. E. and Satope, P. (2016) Design of a beam structure for failure prevention at critical loading conditions. International Academic Journal of Innovative Research, 3(10), 32-44.

[12]. Lloyd, S. (1993) Regulation of the certification of wind energy conversion systems, rules and regulations IV: Non Marine Technology Part 1, Wind Energy, Hamburg.
[13]. Kekezoglu, B., Tanrıoven, M. and Erduman, A. (2015) A new wind turbine concept: design and implementation. Acta Polytechnica Hungarica, 12(3), 199-211.

[14]. Ikpe, A. E., Owunna, I. and Satope, P. (2018) Finite element analysis of aircraft tire behavior under overloaded aircraft landing phase. Aeronautics and Aerospace Open Access Journal, 2(1), 34-39.

[15]. Budynas RG, Nisbett JK. (2008) Shigley's mechanical engineering design. McGraw-Hill New York, ISBN: 978-007-126896-7.

[16]. Kallesoe, B. S. and Hansen, M. H. (2009) Some effects of large blade deflections on aeroelastic stability. 4th AIAA Aerospace Sciences Meeting, American Institute of Aeronotics and Astronautics, 5-8 January, 2009, Orlando, Florida.

[17]. Sompong, N. and Prombut, P. (2017) Effects of bend-twist coupling deformation on on the aerodynamic performance of a wind turbine blade. International Journal of GEOMATE, 34(34), 15-20.

[18]. Arnett, E. B., Schirmacher, M., Huso, M. M., Hayes, J. P. (2010) Effectiveness of changing wind cut-in speed to reduce Bat fatalities at wind facilities. Bats and Wind Energy Coperative, Bats Conservation International, Texas, USA.

[19]. Astolfi, D. and Castellani, F. (2019) Wind turbine power curve upgrades: part II. Energies, 12 (1503), 1-20.

[20]. Pechlivanoglou, G. K., Wagner, J., Nayeri, C. N. and Paschereit, C. O. (2010) Active aerodynamic control of wind turbine blades with high deflection flexible flaps. $48^{\text {th }}$ AIAA Aerospace Sciences Meeting, American Institute of Aeronotics and Astronautics, 4-7 January, 2010, Orlando, Florida. 